\title{
A cohort of Indigenous Australian women and their children through pregnancy and beyond: the Gomeroi gaaynggal study
}

\author{
A. M. Ashman ${ }^{1,2}$, C. E. Collins ${ }^{2}$, L. Weatherall ${ }^{1,3}$, L. J. Brown ${ }^{4}$, M. E. Rollo ${ }^{2}$, D. Clausen ${ }^{5}$, C. C. Blackwell ${ }^{6,7}$, \\ K. G. Pringle ${ }^{3,6}$, J. Attia ${ }^{8}$, R. Smith ${ }^{3}$, E. R. Lumbers ${ }^{3,6}$ and K. M. Rae Ra,3* $^{1,3}$ \\ ${ }^{1}$ Gomeroi gaaynggal Centre, Faculty of Health and Medicine, The University of Newcastle, Tamworth, NSW, Australia \\ ${ }^{2}$ Priority Research Centre in Physical Activity and Nutrition, School of Health Sciences, Faculty of Health and Medicine, The University of Newcastle, Callaghan, \\ NSW, Australia \\ ${ }^{3}$ Mothers and Babies Research Centre, Hunter Medical Research Institute, John Hunter Hospital, New Lambton, NSW, Australia \\ ${ }^{4}$ Department of Rural Health, Faculty of Health and Medicine, The University of Newcastle, Tamworth, NSW, Australia \\ ${ }^{5}$ Pathology North, New South Wales Health, Tamworth, NSW, Australia \\ ${ }^{6}$ School of Biomedical Sciences and Pharmacy, Faculty of Health and Medicine, The University of Newcastle, Callaghan, NSW, Australia \\ ${ }^{7}$ Information Based Medicine, Hunter Medical Research Institute, John Hunter Hospital, New Lambton, NSW, Australia \\ ${ }^{8}$ Clinical Research Design, IT, and Statistical Support Unit, Hunter Medical Research Institute, John Hunter Hospital and University of Newcastle, New Lambton, \\ NSW, Australia
}

Indigenous Australians have high rates of chronic diseases, the causes of which are complex and include social and environmental determinants. Early experiences in utero may also predispose to later-life disease development. The Gomeroi gaaynggal study was established to explore intrauterine origins of renal disease, diabetes and growth in order to inform the development of health programmes for Indigenous Australian women and children. Pregnant women are recruited from antenatal clinics in Tamworth, Newcastle and Walgett, New South Wales, Australia, by Indigenous research assistants. Measures are collected at three time points in pregnancy and from women and their children at up to eight time points in the child's first 5 years. Measures of fetal renal development and function include ultrasound and biochemical biomarkers. Dietary intake, infant feeding and anthropometric measurements are collected. Standardized procedures and validated tools are used where available. Since 2010 the study has recruited over 230 women, and retained 66 postpartum. Recruitment is ongoing, and Gomeroi gaaynggal is currently the largest Indigenous pregnancy-through-early-childhood cohort internationally. Baseline median gestational age was 39.1 weeks $(31.5-43.2, n=110)$, median birth weight was $3180 \mathrm{~g}(910-5430 \mathrm{~g}, n=110)$. Over one third (39.3\%) of infants were admitted to special care or neonatal nursery. Nearly half of mothers (47.5\%) reported tobacco smoking during pregnancy. Results of the study will contribute to knowledge about origins of chronic disease in Indigenous Australians and nutrition and growth of women and their offspring during pregnancy and postpartum. Study strengths include employment and capacity-building of Indigenous staff and the complementary ArtsHealth programme.

Received 23 August 2015; Revised 7 February 2016; Accepted 13 February 2016; First published online 15 April 2016

Key words: aboriginal, diabetes, Indigenous, nutrition, renal

\section{Introduction}

Internationally there are an estimated 370 million people across 70 countries who self-identify as Indigenous, including Aboriginal and Torres Strait Islander people of Australia, Maori people of New Zealand, Indigenous people of the Americas, and the Sami or Laplander people of northern Scandinavia. ${ }^{1,2}$ Disparities in Indigenous and non-Indigenous health continue worldwide. In both economically developed and developing nations where Indigenous people reside, Indigenous people experience poorer health status than the overall population. ${ }^{3}$ There are significant disparities in birth outcomes for Indigenous people in Australia, New Zealand, the United States and Canada, including higher rates of still birth, infant

*Address for correspondence: Dr K. Rae, Gomeroi gaaynggal Centre, Faculty of Health and Medicine, The University of Newcastle, 2/1 Hinkler Road, Tamworth, NSW 2340, Australia.

(Email kym.rae@newcastle.edu.au) mortality and preterm birth for Indigenous infants compared with non-Indigenous. ${ }^{4}$ Indigenous infants in Australia and the United States are more likely to be of low birth weight. ${ }^{4}$ Prospective pregnancy cohort studies of Indigenous peoples are unfortunately scarce, as they may be of great value in determining the causes and trajectories of poor health in these populations.

Indigenous Australians have a life expectancy 10 years lower than non-Indigenous Australians. ${ }^{5}$ Renal disease, diabetes, overweight and cardiovascular diseases are particularly prevalent in Indigenous Australians, ${ }^{6,7}$ and are significant risk factors for development of hypertension and stroke. In 2012-2013, heart disease affected around 12\% of Indigenous Australians. ${ }^{7}$ Overweight and obesity are significant public health concerns in Australia, with Indigenous Australians 1.6 times as likely to be obese as non-Indigenous Australians. ${ }^{8}$ In 2012-2013, 66\% of Indigenous Australians over 15 years of age were overweight or obese. ${ }^{8}$ 
The prevalence of preterm and low birth weight babies is higher for Indigenous Australians than for non-Indigenous women. ${ }^{9}$ In 2012, 14.3\% of babies of Indigenous mothers were born preterm, a greater proportion than the $8.3 \%$ of babies born preterm to non-Indigenous mothers. ${ }^{9}$ The proportion of babies born of low birth weight $(<2500 \mathrm{~g})$ to Indigenous mothers $(11.8 \%)$ was nearly twice that as low birth weight babies born to non-Indigenous mothers $(6.0 \%){ }^{9}$

There are many contributing factors to the continuing inequalities in health experiences and life expectancy, including a long history of colonisation and oppression in many of these countries resulting in a legacy of political, economic and social disadvantage for Indigenous peoples. Social and environmental determinants of health include education, employment and income, nutrition, breastfeeding, tobacco use and chronic infections. Optimal nutrition is a crucial factor influencing growth and development and is protective against ill-health. Healthy growth in the early years of life can be a good indicator of a child's health and nutritional status. The National Aboriginal and Torres Strait Islander Nutrition and Physical Activity Survey (NATSINPAS) identified areas for improvement in terms of dietary intake for Indigenous Australians, including increasing vegetable and fruit consumption and decreasing foods that are nutrient-poor and energy-dense. ${ }^{10}$ Food insecurity can contribute to poor nutrient intake, and the NATSINPAS found that over one fifth of Indigenous Australians were living in a household where someone went without food when food ran out. ${ }^{10}$ Breastfeeding provides both short and long-term health benefits for mother and child. In 2012-2013, the rate of any breastfeeding was $83 \%$ for Indigenous children and $93 \%$ for non-Indigenous children. ${ }^{8}$ Nearly half (44\%) of Indigenous Australians aged 15 and over reported being tobacco smokers in 2012-2013. ${ }^{8}$

There is evidence that many chronic diseases have their origins in the intrauterine environment. David Barker proposed and provided epidemiological evidence that under-nutrition during intrauterine life predisposed to earlier onset of chronic disease; poor supply of nutrients programmes structural and functional changes in the metabolism of the developing fetus to anticipate an extrauterine environment with low nutrient availability. ${ }^{11-13}$ Barker $e t$ al. showed that low birth weight was associated with an increased risk of coronary heart disease, hypertension, stroke and type 2 diabetes mellitus later in life. ${ }^{11,12}$ This risk is heightened in children with low weight gain in the first 2 years of life, especially if followed by rapid increases in body fat mass when a high energy diet is consumed that conflicts with that anticipated from the intrauterine experience. ${ }^{11}$

The functional units of the human kidney (nephrons) are formed by 34 weeks of gestation. Once formed, the number of nephrons in each kidney at birth will not change throughout life. A low nephron number predisposes an individual to chronic renal disease later in life. ${ }^{14}$ Babies born early, particularly those born before 34 weeks, and those born small for gestational age are more likely to have low nephron numbers. A low nephron number will result in compensatory hyperfiltration by existing nephrons, making these nephrons prone to failure and leading to impaired renal function. Indigenous people are more likely to have a reduction in nephron number. ${ }^{14}$ In 2012-2013 Indigenous Australians were twice as likely as non-Indigenous Australians (rate ratio 2:1) to have signs of chronic kidney disease (CKD) (after adjusting for age), with almost one fifth of Aboriginal and Torres Strait Islander people aged $\geqslant 18$ years having indicators of CKD in 2012-2013. ${ }^{15}$ The rate of CKD for Indigenous women was $16.9 \%$ in 2012-2013, and Indigenous women are more likely to have kidney disease than non-Indigenous women (rate ratio 3.6). ${ }^{7,15}$ Rates of CKD are particularly high in remote areas of Australia where $33.6 \%$ of people were identified as having indicators of CKD in 2012-2013, compared with $13.1 \%$ of people living in non-remote areas. ${ }^{15}$ Diabetes, which poses a high risk for development of early onset renal disease, is also more prevalent in Indigenous Australians. ${ }^{15}$ Aboriginal and Torres Strait Islander people are more than three times as likely to have diabetes than nonIndigenous Australians with $11 \%$ of the Indigenous population identified as having diabetes, diagnosed by fasting plasma glucose test $(\geqslant 7.0 \mathrm{mmol} / \mathrm{l}$ indicative of diabetes) and glycated haemoglobin test $(\mathrm{HbA} 1 \mathrm{c} \geqslant 6.5 \%)$ in the Australian Aboriginal and Torres Strait Islander Health Survey 2012-2013. ${ }^{15}$

Preterm birth contributes to the prevalence of low birth weight in babies and to the subsequent predisposition to chronic disease development. There is evidence of a relationship between stress during pregnancy and preterm birth. ${ }^{16}$ Stressors for Indigenous women include; chronic pre-existing renal disease, chronic infections, cigarette smoking and passive exposure to smoke, and poor nutrition. Social stressors include exposure to major life events (e.g. death of a loved one) and racism. In 2012-2013, Indigenous Australians were 2.7 times as likely as non-Indigenous Australians to experience high levels of psychological distress (major stressors included death of a family member or close friend, serious illness, unemployment, mental illness or problems with drugs or alcohol $)^{8}$. Racism is a significant problem. In 2012-2013, 16\% of Indigenous Australians felt they had been treated badly because they were Indigenous. ${ }^{8}$

Smith et al. have previously reported on the 'placental clock': a determinant of the length of human pregnancy gestation. ${ }^{17}$ Placental secretion of corticotropin-releasing hormone (CRH) and maternal plasma concentrations of CRH rise exponentially during pregnancy, coinciding with a fall in concentration of $\mathrm{CRH}$ binding protein late in pregnancy. The subsequent surge in CRH bioavailability coincides with the onset of parturition, implying that high CRH acts as a prompt for the birth of offspring. ${ }^{17}$ In women who deliver preterm babies, the hormone rises more rapidly than normal. The release of CRH is triggered by activation of the hypothalamic pituitary axis and its stimulation of the stress-hormone cortisol, causing a positive feed-forward system (see Fig. 1). Therefore any stress in the pregnant woman's life may result in preterm birth, and low birth weight infants. Exploring the reasons for stress-related 


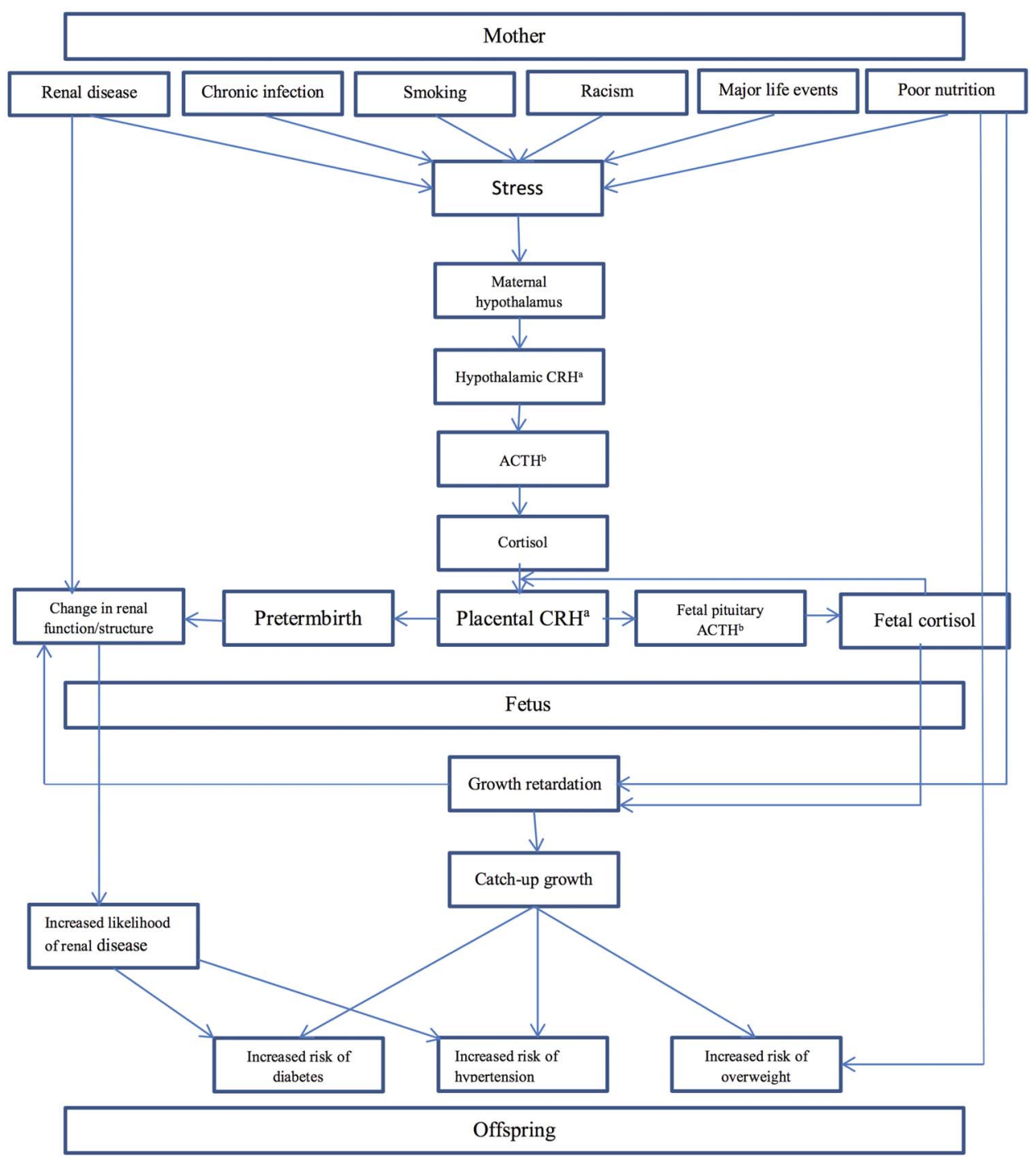

Fig. 1. Pathways to Poor Health Outcomes in Young Indigenous Australians People Key: ${ }^{\mathrm{a}} \mathrm{CRH}$, corticotrophin-releasing hormone; ${ }^{\mathrm{b}} \mathrm{ACTH}$, adrenocorticotropic hormone.

hypercortisolaemia and methods for its prevention will potentially reduce the incidence of preterm birth of small babies.

The Gomeroi gaaynggal (Gomeroi babies) study aims to explore the relationship between exposure to stressors in the intrauterine environment and offspring health and growth outcomes (Fig. 1). A specific aim is to investigate the developmental origins of renal disease and diabetes in Indigenous people, and in doing so to develop methods for the early detection and prevention of these chronic diseases.

\section{Method}

\section{Study design and setting}

The Gomeroi gaaynngal study is a prospective longitudinal cohort of Indigenous mother-child dyads during pregnancy and up until the children are aged 5 years.
The study is primarily conducted at the Gomeroi gaaynggal centre, a facility of the University of Newcastle in Tamworth, New South Wales (NSW), Australia. NSW has the largest population of Indigenous Australians of any Australian state, with one third of the country's Indigenous peoples residing here. ${ }^{18}$ The 2011 census estimated 208,476 Indigenous people resided in NSW out of 669,881 Indigenous Australians in the country. ${ }^{18}$ There are three recruitment sites in NSW for the study: Tamworth (rural town), Newcastle (regional city) and Walgett (remote town).

The Gomeroi gaaynggal centre was established within walking distance of the Tamworth Aboriginal community to facilitate access and reduce socioeconomic barriers to recruitment and retention. Tamworth is in the Hunter New England region of NSW. As of 2012, the population of the Tamworth region was 58,922 persons. ${ }^{19}$ In the 2011 census, $8.4 \%$ of the Tamworth regional population identified as Aboriginal and/or Torres Strait Islander. ${ }^{19}$ 
Newcastle is a coastal city in Hunter New England. The population of the Newcastle local government area in 2012 was 157,273 persons, of whom a small percentage $(2.6 \%)$ identified as Aboriginal or Torres Strait Islander in the 2011 census. $^{20}$

Walgett is a small remote town in northwest NSW. In the 2011 census, 823 of the 1626 counted residents in Walgett identified as Aboriginal or Torres Strait Islander (99\% of whom identified as Aboriginal). ${ }^{21}$ This figure may be a modest estimation, as the Australian Bureau of Statistics estimated that nationally the Aboriginal 'undercount' was $17 \% .{ }^{21}$

\section{Community consultation}

Before commencing the study, researchers engaged in a 2-year process of community consultation with Indigenous stakeholders, including Elders, mothers' groups, schools, employment agencies and local Indigenous health organizations. ${ }^{22}$ Through this consultation it was determined that the research would occur concurrently with a programme that would provide immediate benefits to the community. An ArtsHealth programme for women in pregnancy and postdelivery was established. As part of the programme, a local Indigenous Elder and artist offers art mentorship and visiting health professionals and health students come to discuss a range of health topics. The programme offers a safe space, informal health information, contacts in the health services and resources to empower Indigenous women to make active changes to improve their health and that of their children. Further details of this community consultation and its outcomes have been published elsewhere. ${ }^{22}$

\section{Ethics approval}

The Gomeroi gaaynggal study received ethics approval from the following committees: the Hunter New England Human Research Ethics Committee (reference number 08/05/21/ 4.01); the New South Wales Human Research Ethics Committee (reference number HREC/08/HNE/129); and the Aboriginal Health and Medical Research Council (reference number 654/08). Protocols are in place to ensure participants are referred to the appropriate health services if adverse results are found. Participants receive no reimbursements or financial incentives to participate.

\section{Recruitment}

Recruitment began in 2010 and is continuing at the time of publication. In Tamworth, participants are recruited by Indigenous research assistants at one of two antenatal clinic locations, including an Indigenous antenatal birth service. In Walgett, recruitment is conducted by an Indigenous research assistant at the Walgett Aboriginal Medical Service. In Newcastle, recruitment was through Birra-li, the Indigenous antenatal birth services. Engaging with and retaining the Newcastle cohort however proved difficult, and recruitment no longer occurs at this site. Pregnant women who identify as Indigenous Australians, or pregnant non-Indigenous women with Indigenous partners are eligible to participate and can enrol at any stage in their pregnancy. From 3 months postpartum, mother and infant dyads are eligible for the follow-up study. Participants give written, informed consent to participate in the pregnancy study and provide renewed consent to continue into the postpartum follow-up study.

Data are collected once per trimester during pregnancy, four times during the infant's first year of life, $(3,6,9$ and 12 months) and when the child is aged 2 years. Where there are indicators of potential renal impairment in either mother or child, participant dyads are followed up until the child is aged 5 years. While attempts are made to see participants as close to these ages as possible, data collection is undertaken at times to suit participants.

Data collected at each time point for women participating in the Gomeroi gaaynggal study are shown in Table 1. Table 2 outlines the data collected at each time point for their children. Details of these variables are described below.

\section{Biochemical data}

Biological samples (maternal blood, urine and saliva, fetal cord blood and child urine) are collected at various time points throughout the study (Tables 1 and 2).

Biochemical measures assessed include: (i) plasma and urinary protein, electrolytes, urea, creatinine; (ii) serum cystatin C; (iii) urinary and plasma glucose; (iv) full blood cell count (including white cell count); (v) immunoglobulins; (vi) total immunoglobulin classes (IgA, IgG and $\operatorname{IgM}$ ) and $\operatorname{IgG}$ specific for Helicobacter pylori; (vii) red cell folate; (viii) Vitamin B12; (ix) cortisol; (x) cotinine. The efficacy of novel renal biomarkers in this population which is at risk of CKD is being investigated.

In addition, we use the samples to examine markers of cardiovascular and kidney function in this cohort of Indigenous women in pregnancy.

Samples in the form of whole blood, serum, plasma, urine and saliva have been stored at $-80^{\circ} \mathrm{C}$ in aliquots of $1 \mathrm{ml}$ to reduce the impact of freeze-thaw on samples for future use.

\section{Blood pressure and ultrasound}

Maternal blood pressure is taken using a Riester re-champion ${ }^{\circledR}$ blood pressure machine and cuff. Infants' blood pressure is taken at each study visit from 3 months of age. A GE CRITI$\mathrm{KON}^{\mathrm{TM}}$ DURA-CUF ${ }^{\mathrm{TM}}$ blood pressure cuff for infants $(8-13 \mathrm{~cm}$ circumference) is used.

Ultrasound scans are conducted using a Phillips Cx50 Portable Diagnostic Ultrasound with a $5 \mathrm{MHz}$ convex transducer. Gestational age, single or multiple pregnancy, fetal anomalies and viability, and estimated date of delivery are determined at the first trimester scan. In the second trimester, fetal morphology and signs of abnormality are checked. In the final trimester renal arteries, umbilical arterial Dopplers and liquor volume are assessed. Fetal measurements 
Table 1. Data collected of mothers at each study visit for the Gomeroi gaaynggal cohort

\begin{tabular}{|c|c|c|c|c|c|c|c|c|c|c|c|}
\hline \multirow[b]{2}{*}{ Data collected } & \multicolumn{3}{|c|}{ Pregnancy } & \multicolumn{8}{|c|}{ Postnatal } \\
\hline & $1 \mathrm{~T}$ & $2 \mathrm{~T}$ & $3 \mathrm{~T}$ & $3 \mathrm{~m}$ & $6 \mathrm{~m}$ & $9 \mathrm{~m}$ & $12 \mathrm{~m}$ & $2 y$ & $3 y$ & $4 y$ & $5 y$ \\
\hline \multicolumn{12}{|l|}{ Anthropometry } \\
\hline Maternal anthropometry: InBody weight and body composition & $\checkmark$ & $\checkmark$ & $\checkmark$ & $\checkmark$ & $\checkmark$ & $\checkmark$ & $\checkmark$ & $\checkmark$ & $\checkmark$ & $\checkmark$ & $\checkmark$ \\
\hline Maternal anthropometry: height & $\checkmark$ & & & & & & & & & & \\
\hline Maternal anthropometry: girths & & & & $\checkmark$ & $\checkmark$ & $\checkmark$ & $\checkmark$ & $\checkmark$ & $\checkmark$ & $\checkmark$ & $\checkmark$ \\
\hline Maternal pre-pregnancy weight (self-reported) & $\checkmark$ & & & & & & & & & & \\
\hline \multicolumn{12}{|l|}{ Samples collected } \\
\hline Maternal blood sample & $\checkmark$ & $\checkmark$ & $\checkmark$ & $\checkmark$ & $\checkmark$ & & $\checkmark$ & $\checkmark$ & & & \\
\hline Maternal urine sample & & $\checkmark$ & $\checkmark$ & & $\checkmark$ & & $\checkmark$ & $\checkmark$ & & & \\
\hline Maternal saliva collection & $\checkmark$ & $\checkmark$ & $\checkmark$ & & & & & & & & \\
\hline \multicolumn{12}{|l|}{ Blood pressure } \\
\hline Maternal blood pressure & $\checkmark$ & $\checkmark$ & $\checkmark$ & $\checkmark$ & $\checkmark$ & $\checkmark$ & $\checkmark$ & $\checkmark$ & $\checkmark$ & $\checkmark$ & $\checkmark$ \\
\hline \multicolumn{12}{|l|}{ Dietary intake } \\
\hline Maternal nutrient supplementation history & & & & $\checkmark$ & & & & & & & \\
\hline Maternal $24 \mathrm{~h}$ recall & $\checkmark$ & & $\checkmark$ & $\checkmark$ & $\checkmark$ & $\checkmark$ & $\checkmark$ & $\checkmark$ & $\checkmark$ & $\checkmark$ & $\checkmark$ \\
\hline Australian eating survey & & & $\checkmark$ & & $\checkmark$ & & $\checkmark$ & $\checkmark$ & $\checkmark$ & $\checkmark$ & $\checkmark$ \\
\hline \multicolumn{12}{|l|}{ Other } \\
\hline Maternal and child health questionnaire: full & & & & $\checkmark$ & & & & & & & \\
\hline Maternal and child health questionnaire: review & & & & & $\checkmark$ & $\checkmark$ & $\checkmark$ & $\checkmark$ & $\checkmark$ & $\checkmark$ & $\checkmark$ \\
\hline Maternal psychosocial survey & $\checkmark$ & $\checkmark$ & $\checkmark$ & & & & & & & & \\
\hline
\end{tabular}

$\mathrm{T}$, trimester; m, months; $\mathrm{y}$, years.

Table 2. Data collected of offspring at each study visit for the Gomeroi gaaynggal cohort

\begin{tabular}{|c|c|c|c|c|c|c|c|c|c|c|c|}
\hline \multirow[b]{2}{*}{ Data collected } & \multicolumn{3}{|c|}{ Pregnancy } & \multicolumn{8}{|c|}{ Postnatal } \\
\hline & $1 \mathrm{~T}$ & $2 \mathrm{~T}$ & $3 \mathrm{~T}$ & $3 \mathrm{~m}$ & $6 \mathrm{~m}$ & $9 \mathrm{~m}$ & $12 \mathrm{~m}$ & $2 y$ & $3 y$ & $4 y$ & $5 y$ \\
\hline Fetal ultrasound scan & $\checkmark$ & $\checkmark$ & $\checkmark$ & & & & & & & & \\
\hline \multicolumn{12}{|l|}{ Anthropometry } \\
\hline Child anthropometry: length or height, weight, skinfold thicknesses and girths & & & & $\checkmark$ & $\checkmark$ & $\checkmark$ & $\checkmark$ & $\checkmark$ & $\checkmark$ & $\checkmark$ & $\checkmark$ \\
\hline \multicolumn{12}{|l|}{ Samples collected } \\
\hline \multicolumn{12}{|l|}{ Cord blood: taken immediately post-delivery } \\
\hline Child blood sample & & & & & & & $\checkmark$ & $\checkmark$ & & & \\
\hline Infant urine $\mathrm{a}^{\mathrm{a}}$ & & & & $\checkmark$ & $\checkmark$ & $\checkmark$ & $\checkmark$ & $\checkmark$ & $\checkmark$ & $\checkmark$ & $\checkmark$ \\
\hline \multicolumn{12}{|l|}{ Blood pressure } \\
\hline Child blood pressure & & & & $\checkmark$ & $\checkmark$ & $\checkmark$ & $\checkmark$ & $\checkmark$ & $\checkmark$ & $\checkmark$ & $\checkmark$ \\
\hline \multicolumn{12}{|l|}{ Dietary intake } \\
\hline Infant feeding questionnaire & & & & $\checkmark$ & $\checkmark$ & $\checkmark$ & $\checkmark$ & & & & \\
\hline Current feeding practices questionnaire & & & & $\checkmark$ & $\checkmark$ & $\checkmark$ & $\checkmark$ & & & & \\
\hline Child $24 \mathrm{~h}$ recall & & & & & & $\checkmark$ & $\checkmark$ & $\checkmark$ & $\checkmark$ & $\checkmark$ & $\checkmark$ \\
\hline Australian child and adolescent eating survey & & & & & & & & $\checkmark$ & $\checkmark$ & $\checkmark$ & $\checkmark$ \\
\hline \multicolumn{12}{|l|}{ Other } \\
\hline Maternal and child health questionnaire: full & & & & $\checkmark$ & & & & & & & \\
\hline Maternal and child health questionnaire: review & & & & & $\checkmark$ & $\checkmark$ & $\checkmark$ & $\checkmark$ & $\checkmark$ & $\checkmark$ & $\checkmark$ \\
\hline
\end{tabular}

$\mathrm{T}$, trimester; $\mathrm{m}=$ months; $\mathrm{y}$, years

${ }^{a}$ Urine sample either from nappy or collection from child, as appropriate.

of head circumference, abdominal circumference and femur length are calculated to estimate fetal weight at each scan; fetal growth is monitored throughout pregnancy. Fetal kidney measures are anterior-posterior, transverse and length. These are taken as soon as the kidneys can be visualized and kidney volume is calculated from these measures. ${ }^{23}$ 


\section{Questionnaires}

\section{Nutritional assessment}

Measures of dietary intake of women and infants are collected via:

(i) Food Frequency Questionnaires: the Australian Eating Survey for mothers ${ }^{24}$ and the Australian Child and Adolescent Eating Survey for children; ${ }^{25}$

(ii) Infant Feeding Recall (IFR) collects information on initiation and duration of breastfeeding and if infants have regularly consumed the following (and age of initiation): infant formula; cow's milk (as a drink); milk substitutes; solid foods. Questions for the IFR were selected from the NSW Child Health Survey 2001 and the 1995 National Nutrition Survey; ${ }^{26,27}$

(iii) Current Feeding Practices (CFP) questionnaire asks mothers about their child's sources of nutritional intake in the $24 \mathrm{~h}$ preceding the interview, including intake of: vitamin or mineral supplements; medicine; plain water; sweetened or flavoured water (e.g. soft drinks or cordial); fruit juice; tea or infusion; oral rehydration salts; any other food or fluids. The CFP is based on the recommendations of Webb et al. ${ }^{28}$ Both the IFR and CFP have been used in other cohort studies of women and their children in pregnancy and beyond; ${ }^{29}$

(iv) Twenty-four hour food recalls of mothers and infants (via mothers) are conducted to report all food and fluid intake in the $24 \mathrm{~h}$ preceding the interview day.

\section{Psychosocial assessment}

Validated psychosocial tests are all self-administered to determine aspects of psychosocial health for the women participating in the study:

(i) Stressful Life Events (an excerpt from the National Aboriginal and Torres Strait Islander Health Survey [NATSIHS]). The Stressful Life Events survey has been validated in Indigenous populations; ${ }^{30}$

(ii) Impact of Event Scale (revised). The Impact of Event scale has not been validated in Indigenous people, however it has been used in a variety of population groups by Wadhwa et al.; ${ }^{31}$

(iii) Kessler $10+$. The Kessler $10+$ has been found to be a useful tool for measuring psychological distress in middle-aged and older Indigenous Australians; ${ }^{32}$

(iv) Discrimination survey (excerpt from the NATSIHS). The Discrimination survey has been validated in Indigenous populations. $^{30}$

Additional questionnaires elicit information for:

(i) medical history;

(ii) self-reported tobacco use;

(iii) self-reported alcohol consumption

(iv) maternal age, employment status, and educational attainment.
Details of previous pregnancy history, family medical history and gynaecological history, and offspring's gender, birth weight and Activity, Pulse, Grimace, Appearance, and Respiration (APGAR) score, are obtained through the Obstetrics database set, antenatal records and the midwives birth register.

\section{Anthropometry}

Anthropometric measures are performed by an Accredited Practising Dietician (APD) with Level One Anthropometrist certification from the International Society for the Advancement of Kinanthropometry (ISAK). All circumferences, girths, skinfold thicknesses, and lengths are measured in accordance with the ISAK protocol. ${ }^{33}$ Measurements include:

(i) maternal pre-pregnancy weight (self-reported);

(ii) maternal height;

(iii) maternal body composition obtained using InBody $720^{\mathrm{TM}}$ bioelectrical impedance scales (Biospace Co., Ltd., Seoul, South Korea) including body mass index, visceral fat area, body fat mass, skeletal muscle mass, total body water and body fat percentage;

(iv) at each postpartum study visit maternal girths and circumferences are obtained including: mid-upper arm, waist, gluteal, upper thigh and calf;

(v) infant weight is obtained at each postpartum visit using infant scales;

(vi) infant length is measured crown-to-heel at each postpartum visit;

(vii) infant girths and circumferences: head, mid-upper arm, abdomen (at level of umbilicus), mid-thigh and calf;

(viii) skinfold thicknesses of infants are obtained using Harpenden skinfold calipers at the following sites: subscapular, biceps, iliac crest, front thigh and medial calf. ${ }^{33}$

\section{Data management}

Participants are given unique study identification numbers in order to avoid labelling documentation with identifying details. Data are collected either electronically or on paper, and is transferred to electronic storage. Data are stored electronically in excel spreadsheets only available to members of the research team. Paper data are coded and stored in locked filing cabinets accessible by the research team only.

\section{Results}

Recruitment for the Gomeroi gaaynggal study is ongoing. At the time of manuscript preparation, 236 mother-child dyads have been recruited into the study in their pregnancy. There has been a loss to this cohort of 76 women, including 21 women who have either withdrawn or declined to participate in followup; 23 women who have moved from the study sites before consenting to participate; and a further seven women who have either miscarried or withdrawn due to infant death. The Newcastle cohort of 25 women is not eligible for follow-up 


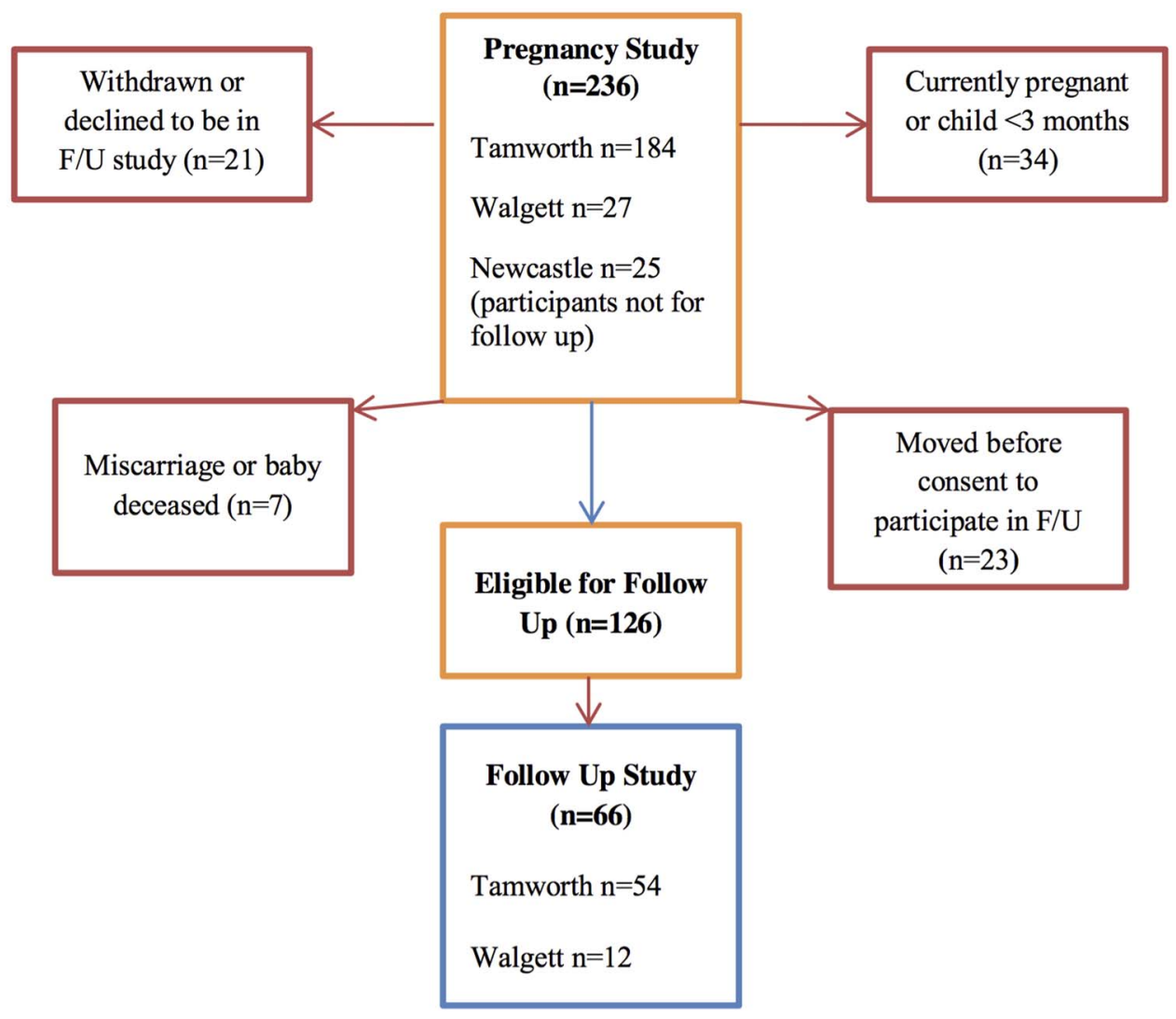

Fig. 2. Gomeroi gaaynggal study numbers.

given the difficulties with accessing this population. In addition 34 women are at the time of writing either currently pregnant or have infants $<3$ months of age. Of the 126 women currently eligible for participation in the postpartum follow-up study, over half $(52 \% n=66)$ have been retained and are attending study visits to date (see Fig. 2).

Preliminary results from a baseline sample of $n=110$ participant dyads are presented below. The data generally reflected a higher prevalence of values outside normal ranges.

\section{Pregnancy outcomes}

Baseline characteristics of mothers are displayed in Table 3. Just over $6 \%$ of participants were recorded as having gestational diabetes (diagnosed by a fasting glucose of $\geqslant 5.5 \mathrm{mmol} / \mathrm{l}$ ) in their current pregnancy, and $2.6 \%$ had type 2 diabetes mellitus. In the general population, 3-8\% of pregnant women will develop gestational diabetes. ${ }^{34}$ Median gestational age for this cohort was 39.1 weeks (range: 31.5-43.2, $n=110$ ), and median birth weight of infants was $3180 \mathrm{~g}(910-5430 \mathrm{~g}$, $n=110$ ). Median birth weight was $3093 \mathrm{~g}$ for females (range: $1620-5430 \mathrm{~g}, n=46)$ and $3078 \mathrm{~g}$ for males $(910-5170 \mathrm{~g}$, $n=54)$. The majority of infants born in this cohort had APGAR scores $>7$ (82.2\%), and $4.4 \%$ had scores $0-3$.
Over a third of infants (39.3\%) had admission to special care or neonatal care nursery. The twinning rate for this cohort was $4.8 \%$. Further pregnancy outcomes are displayed in Table 4.

\section{Risk factors for chronic disease}

Median plasma total cholesterol for women in the cohort was $5.9 \mathrm{mmol} / \mathrm{l}$ (range: $2-8.6, n=195$ ), averaged over all study visits in pregnancy. Levels above $4 \mathrm{mmol} / \mathrm{l}$ indicate increased risk of coronary heart disease, though hypercholesterolaemia naturally occurs in pregnancy. Median plasma triglycerides were $2.4 \mathrm{mmol} / \mathrm{l}(0.3-7.3, n=192$, reference range $<2 \mathrm{mmol} / \mathrm{l})$. Cholesterol and triglyceride levels of participants will continue to be monitored postpartum. Median plasma glucose was $4.4 \mathrm{mmol} / \mathrm{l}(2.4-12.8, n=208$, reference range $3.5-7.8 \mathrm{mmol} / \mathrm{l}$ random plasma glucose for adults). Nearly half of the cohort to date reported being a tobacco smoker during their pregnancy $(47.5 \%)$. Eleven women who reported being non-smokers had detectable levels of cotinine but in only two of these women were plasma cotinine levels $>1.0 \mathrm{ng} / \mathrm{ml}$. This corresponds with national data where smoking during pregnancy was reported by $48 \%$ of Indigenous mothers in $2012^{9}$. Further results are displayed in Tables 4 and 5. 
Table 3. Baseline characteristics of participants in the Gomeroi gaaynggal study

\begin{tabular}{|c|c|c|c|c|}
\hline & & Mean (S.D.) & Range & Median \\
\hline Age (years) & & $26(5.9)$ & $13.8-40.9$ & 25 \\
\hline Current diabetes status & & $\%$ & & \\
\hline $\begin{array}{l}\text { Diabetes Type I } \\
\text { Diabetes Type II } \\
\text { Gestational diabetes }\end{array}$ & & $\begin{array}{l}1.03 \\
2.56 \\
6.15\end{array}$ & & \\
\hline Past pregnancy history & & $\%$ & Range & \\
\hline Total number past pregnancies & $\begin{array}{l}\leqslant 1 \\
2-4 \\
5-9 \\
\geqslant 10\end{array}$ & $\begin{array}{r}17.07 \\
50.00 \\
28.06 \\
4.88\end{array}$ & $0-23$ & \\
\hline Total number live children & $\begin{array}{l}\leqslant 1 \\
2-4 \\
5-9 \\
\geqslant 10\end{array}$ & $\begin{array}{r}29.27 \\
51.22 \\
19.52 \\
0.00\end{array}$ & $0-9$ & \\
\hline Miscarriages & $\begin{array}{l}\leqslant 1 \\
2-4 \\
5-9 \\
\geqslant 10\end{array}$ & $\begin{array}{c}82.28 \\
12.66 \\
2.53 \\
15.2\end{array}$ & $0-16$ & \\
\hline Termination & $\begin{array}{l}0 \\
1 \\
2 \\
3\end{array}$ & $\begin{array}{r}75.95 \\
17.72 \\
5.06 \\
1.27\end{array}$ & $0-3$ & \\
\hline SUDI & $\begin{array}{l}0 \\
1\end{array}$ & $\begin{array}{r}97.47 \\
2.53\end{array}$ & & \\
\hline Stillbirths & $\begin{array}{l}0 \\
1\end{array}$ & $\begin{array}{r}97.47 \\
2.53\end{array}$ & & \\
\hline
\end{tabular}

SUDI, sudden unexpected deaths in infants.

Table 4. Pregnancy outcomes of participants in the Gomeroi gaaynggal study

\begin{tabular}{|c|c|c|c|c|}
\hline & \multicolumn{4}{|c|}{ Total $(n=110)$} \\
\hline & Mean $(n)$ & Median & S.D. & Range \\
\hline Gestational age at delivery (weeks) & $38.63(110)$ & 39.10 & 1.947 & $31.5-43.2$ \\
\hline BW at delivery $(\mathrm{g})$ & $3179.3(110)$ & 3180.00 & 689.79 & $910-5430$ \\
\hline GROW BW centile 36 & $34.1(109)$ & 25.4 & 29.59 & $0-100$ \\
\hline Baby length at birth $(\mathrm{cm})$ & $49.2(79)$ & 49.00 & 2.29 & $45-55$ \\
\hline Baby head circumference at birth $(\mathrm{cm})$ & $34.37(83)$ & 34.50 & 1.98 & $26-38$ \\
\hline First APGAR measure & $8.09(90)$ & 9.00 & 1.65 & $1-9$ \\
\hline Second APGAR & $8.84(90)$ & 9.00 & 0.997 & $2-10$ \\
\hline
\end{tabular}

GROW BW, gestation related optimal weight birth weight; APGAR, appearance, pulse, grimace, activity, respiration.

\section{Renal function of mothers}

Measures of renal function are presented in Table 5. The mean urinary albumin to creatinine and also protein to creatinine ratios showed $16 \%$ of samples had evidence of clinical proteinuria. Eighteen women (10\% of cohort) had urinary protein to creatinine ratios $\geqslant 30 \mathrm{mg} / \mathrm{mmol}$, and six had more than one sample with proteinuria. Three women with proteinuria had type 1 diabetes, and one woman had gestational diabetes mellitus, therefore proteinuria is unexplained in most samples. These four women were either normotensive or did not have a recorded blood pressure. Only five women ever recorded a systolic blood pressure $\geqslant 140 \mathrm{mmHg}$, and six women a diastolic pressure 
Table 5. Anthropometric, biochemical and haematological measures of participants in the Gomeroi gaaynggal study (combined for all visits during pregnancy)

\begin{tabular}{|c|c|c|c|c|c|}
\hline & Mean $(n)$ & Median & S.D. & Range & Normal range $e^{\mathrm{a}, 37}$ \\
\hline \multicolumn{6}{|l|}{ Body composition } \\
\hline Weight (kg) & $85.3(78)$ & 84 & 23.5 & $45-148$ & \\
\hline Height (cm) & $164.5(109)$ & 164.00 & 6.6 & $152-185$ & \\
\hline Body mass index $\left(\mathrm{kg} / \mathrm{m}^{2}\right)$ & 30.7 (107) & 30 & 8.6 & $15-52$ & \\
\hline$\%$ Body fat $(\%)$ & $41.7(54)$ & 43.6 & 11.2 & $17-63$ & \\
\hline Visceral fat area $\left(\mathrm{cm}^{2}\right)$ & $202(53)$ & 158 & 158 & $38-870$ & \\
\hline Body fat mass (kg) & $38.8(54)$ & 36.9 & 18.9 & $12-84$ & \\
\hline Skeletal muscle mass $(\mathrm{kg})$ & $26.8(54)$ & 26.8 & 3.9 & $18-36$ & \\
\hline Total water (l) & $36(53)$ & 34.7 & 4.7 & $25-48$ & \\
\hline Intracellular water (l) & $22.2(53)$ & 21.4 & 2.9 & $15-29$ & \\
\hline Extracellular water (l) & $13.8(53)$ & 13.3 & 1.8 & $10-19$ & \\
\hline \multicolumn{6}{|l|}{ Blood pressure } \\
\hline Systolic (mmHg) & $113(167)$ & 110 & 13 & $80-150$ & \\
\hline Diastolic (mmHg) & $68(167)$ & 65 & 11 & $45-104$ & \\
\hline \multicolumn{6}{|l|}{ Renal function } \\
\hline Plasma cystatin C (mg/l) & $0.85(206)$ & 0.80 & 0.28 & $0.38-2.1$ & $0.40-0.99$ \\
\hline Plasma sodium $(\mathrm{mmol} / \mathrm{l})$ & $136(209)$ & 135 & 2.2 & $128-145$ & $134-145$ \\
\hline Plasma potassium $(\mathrm{mmol} / \mathrm{l})$ & $4.1(207)$ & 4.0 & 0.5 & $3-6$ & $3.5-5.0$ \\
\hline Plasma creatinine $(\mu \mathrm{mol} / \mathrm{l})$ & $49(208)$ & 48 & 8.9 & $20-83$ & $49-90^{\mathrm{b}}$ \\
\hline Urinary creatinine $(\mathrm{mmol} / \mathrm{l})$ & $10.4(168)$ & 8.7 & 8.2 & $0.1-41.7$ & c \\
\hline Urinary protein $(\mathrm{g} / \mathrm{l})$ & $0.14(170)$ & 0.07 & 0.2 & $0.01-1.9$ & $<0.15$ \\
\hline Urinary protein/creatinine $(\mathrm{mg} / \mathrm{mmol})$ & $25.7(168)$ & 11.8 & 63 & $0-700$ & $<30$ \\
\hline Urinary albumin $(\mathrm{mg} / \mathrm{l})$ & $22(171)$ & 8.00 & 53 & $2-473$ & $<30$ \\
\hline Urinary albumin/creatinine $(\mathrm{mg} / \mathrm{mmol})$ & $2.8(170)$ & 1.4 & 5.461 & $0.2-50$ & $<3.5^{\mathrm{d}}$ \\
\hline \multicolumn{6}{|l|}{ Nutritional biomarkers } \\
\hline Plasma glucose (random) (mmol/l) & $4.6(208)$ & 4.4 & 1.2 & $2.4-12.8$ & $3.5-7.8$ \\
\hline Plasma total cholesterol $(\mathrm{mmol} / \mathrm{l})$ & $6.4(195)$ & 5.9 & 5.9 & $2-8.6$ & $<4$ \\
\hline Plasma triglycerides $(\mathrm{mmol} / \mathrm{l})$ & $2.5(192)$ & 2.4 & 1.1 & $0.3-7.3$ & $<2$ \\
\hline Plasma vitamin B12 (pmol/l) & $169(154)$ & 150 & 74 & 59-403 & $138-652$ \\
\hline Red cell folate $(\mathrm{nmol} / \mathrm{l})$ & $1505(168)$ & 1358 & 750 & $280-4381$ & $285-1475$ \\
\hline \multicolumn{6}{|l|}{ Immune/inflammatory markers } \\
\hline C-reactive protein $(\mathrm{mg} / \mathrm{l})$ & $8.9(180)$ & 5.8 & 13 & $0.2-109$ & $<5.0$ \\
\hline $\operatorname{IgA}(g / l)$ & 7. (162) & 1.7 & 68 & $0.5-862$ & $0.69-3.37$ \\
\hline $\operatorname{IgM}(g / l)$ & $1.2(161)$ & 1.1 & 0.6 & $0.3-3.4$ & $0.48-2.38$ \\
\hline $\operatorname{IgG}(\mathrm{g} / \mathrm{l})$ & $10.4(162)$ & 8.7 & 18.3 & $3.4-240$ & $6.72-14.40$ \\
\hline IgG Helicobacter pylori $(\mathrm{U} / \mathrm{ml})$ & $16.2(101)$ & 8.9 & 17.3 & $2-82$ & c \\
\hline \multicolumn{6}{|l|}{ Full blood count } \\
\hline White blood cells $\left(\times 10^{9} / \mathrm{l}\right)$ & $10.3(177)$ & 10.30 & 2.7 & $3-18$ & $4-11^{\mathrm{e}}$ \\
\hline Red blood cells $\left(\times 10^{12} / 1\right)$ & $4(176)$ & 4.0 & 0.4 & $2.6-5.1$ & $3.8-5.2^{\mathrm{f}}$ \\
\hline Haemoglobin $(g / l)$ & $116(179)$ & 117 & 13.3 & $11-138$ & $115-160^{\mathrm{d}}$ \\
\hline Haematocrit & $0.35(179)$ & 0.35 & 0.03 & $0.25-0.43$ & $0.34-0.47^{\mathrm{d}}$ \\
\hline \multicolumn{6}{|l|}{ Other measures } \\
\hline Plasma cortisol (random) (nmol/l) & $418(154)$ & 423 & 133 & $13-878$ & $80-535$ \\
\hline Cotinine $(\mathrm{ng} / \mathrm{ml})$ & $67(148)$ & 0.8 & 99 & $0-580$ & c \\
\hline
\end{tabular}

${ }^{\mathrm{a}}$ Reference ranges are non-pregnant male/female ranges unless otherwise stated.

${ }^{\mathrm{b}}$ Reference range for females $\geqslant 19$ years old.

${ }^{\mathrm{c}}$ Reference range not defined by laboratory.

${ }^{\mathrm{d}}$ Reference range for adult female.

${ }^{\mathrm{e}}$ Reference range for $>21$ years male and female.

${ }^{\mathrm{f}}$ Reference range for pregnancy $1-42$ weeks gestation.

$\geqslant 90 \mathrm{mmHg}$. Both diastolic pressure and plasma Cystatin C (a measure of glomerular filtration rate) showed gestation dependent increases (all $P<0.001$ ). In this population of
Indigenous Australian women, the incidence of high blood pressure is low, but there is an increased prevalence of proteinuria. 


\begin{tabular}{|c|c|c|c|}
\hline & \multicolumn{2}{|c|}{ The Gomeroi gaaynggal Study } & \\
\hline Biochemical Data & $\begin{array}{l}\text { Ultrasound and Blood } \\
\text { Pressure }\end{array}$ & $\begin{array}{l}\text { Ultrasound and Blood } \\
\text { Pressure }\end{array}$ & Anthropometrics \\
\hline $\begin{array}{l}\text {-Renal Measures } \\
\text { Prorenin } \\
\text { Albumin } \\
\text { Glucose } \\
\text { Uric acid } \\
\text { Renin } \\
\text { Electrolytes } \\
\text { Creatinine } \\
\text { Protein } \\
\text { Angiotensin-converting enzyme } \\
\text { Angiotensin } \\
\text { Cystatin C } \\
\text {-Immunological Measures } \\
\text { Total Ig } \\
\text { IgG for Staph, Bacterial and Viral } \\
\text { PCR } \\
\text { Cytomegalovirus-10 } \\
\text { Heliocobacter pylori } \\
\text {-Metabolic and Cardiovascular } \\
\text { Measures } \\
\text { Homocysteine } \\
\text { B12 } \\
\text { Folate } \\
\text { Transferrin } \\
\text { Liver function tests } \\
\text { Triglycerides } \\
\text { Cholesterol } \\
\text {-Tobacco-by-products } \\
\text { Cotinine } \\
\text {-Stress Hormones } \\
\text { Cortisol } \\
\text { Corticosteroid-binding globulin } \\
\text { Corticotrophin-releasing hormone } \\
\text {-Haematology } \\
\text { Full Blood Count } \\
\text { ABO blood } \\
\text { Lewis blood groups } \\
\text { Haematocrit } \\
\text { Haemoglobin } \\
\text {-Reproductive Health } \\
\text { Estriol } \\
\text { Estradiol } \\
\text { Progesterone }\end{array}$ & $\begin{array}{l}\text {-Blood Pressure } \\
\text {-Ultrasound } \\
\text { Foetal renal volume } \\
\text { Gestational age } \\
\text { Foetal anomaly and viability } \\
\text { Date of delivery } \\
\text { Renal and umbilical arteries } \\
\text { Liquor volume } \\
\text { Estimates of foetal weight }\end{array}$ & $\begin{array}{l}\text {-Nutritional Assessment } \\
\text { Australian Eating Survey } \\
\text { Australian Child and Adolescent } \\
\text { Eating Survey } \\
\text { Infant Feeding Recall } \\
\text { Current Feeding Practices } \\
\text { Maternal } 24 \text { hour recall } \\
\text { Child } 24 \text { hour recall } \\
\text {-Psychosocial Assessment } \\
\text { Stressful Life Events } \\
\text { Kessler 10+ } \\
\text { Discrimination survey } \\
\text {-General Health } \\
\text {-Self-reported Tobacco Use } \\
\text {-Self-reported Alcohol } \\
\text { Consumption } \\
\text {-Demographic and } \\
\text { Socioeconomic information }\end{array}$ & $\begin{array}{l}\text {-Maternal and Child Weight } \\
\text {-Maternal Height } \\
\text {-Child Length } \\
\text {-Maternal Circumferences } \\
\text { Waist } \\
\text { Gluteal } \\
\text { Mid-upper arm } \\
\text { Thigh } \\
\text { Maximum calf } \\
\text {-Child Circumferences } \\
\text { Head } \\
\text { Abdomen } \\
\text { Mid-upper arm } \\
\text { Mid-thigh } \\
\text { Maximum calf } \\
\text {-Child Skinfolds } \\
\text { Subscapular } \\
\text { Bicep } \\
\text { Front thigh } \\
\text { Iliac crest } \\
\text { Medial calf } \\
\text {-Maternal Body Composition } \\
\text { InBody } 720\end{array}$ \\
\hline
\end{tabular}

Fig. 3. Measures in the Gomeroi gaaynggal study.

\section{Discussion}

Current participant numbers are modest and initial difficulties with participant recruitment and retention were overcome through the employment of Indigenous staff, development of community trust, provision of transport and improved access to local health services. In the remote community, the involvement of the Walgett Aboriginal Medical Service has greatly assisted with recruitment. ${ }^{22}$ Recruitment is ongoing and is steadily increasing each year, and the Gomeroi gaaynggal study is currently the largest Indigenous pregnancy-through-early-childhood cohort of its kind.

Irregularity of attendance at antenatal visits has been a limitation and resulted in an irregular sampling schedule.
Additionally, funding was not received to start data collection for the follow-up study for a period of time, and therefore there is a potential loss of follow-up data from the women and children who were early study recruits. The time commitments are particularly burdensome for women with very young children who are in the ongoing follow-up study. In addition, the study design could have been enhanced by collecting psychosocial data in the postnatal period, and collecting pregnancy dietary intake data from the start of the study.

The strengths of this study are many and include the large number of variables measured (see Fig. 3), and the use of validated tools for collection of nearly all variables. The use of cotinine as a biomarker of tobacco use/exposure will be 
validated in Indigenous Australian pregnant women as one of the unique methodologies of this study. Other unique measurements collected include the body composition measures acquired through the InBody $720^{\mathrm{TM}}$ body composition scales. To the authors' knowledge, little work has been done on body composition of Indigenous women during their pregnancy using bioelectrical impendence scales. The regular and systematic measuring of body composition and growth of mothers and their children, and enquiry into their dietary intake, will contribute to what we know about Indigenous nutrition and growth during pregnancy and the postpartum period. Biological samples collected will be revealing as to cardiovascular and kidney function in this cohort of Indigenous women in pregnancy. To our knowledge, these parameters have not been analysed in a similar population of Indigenous pregnant women, and hence the implications for chronic disease are poorly understood.

The study's three locations reflect the diversity of NSW's Indigenous population in regional, rural and remote areas. ${ }^{18}$ Ongoing extensive community engagement involved in the design and founding of the Gomeroi gaaynggal study resulted in the ArtsHealth programme, which has become a popular initiative with women in the local community and an excellent complement to the research components. One of the greatest assets to the study has been the employment of Indigenous staff, who contribute their expertise and community connections and knowledge. Through their work they are given opportunities to increase their research skills and gain professional qualifications that will see research capacity developed by Indigenous communities.

Community consultation is not only essential before conducting research in Indigenous communities, ${ }^{35}$ it is a crucial process for the success of the research study and has valuable benefits for both the researchers and the community. ${ }^{22}$

It is anticipated that earlier recognition of those who are at risk of developing chronic disease (including renal disease and diabetes) and appropriate referrals to health services will lead to better health for participating women and their children. On a larger-scale, the contributions to the literature on early origins of chronic disease amongst Indigenous Australians will greatly assist in the formation of policy, intervention, and health promotion activities aimed at improving health outcomes for this vulnerable population.

\section{Acknowledgements}

The authors wish to acknowledge the traditional custodians of the land: the Gomeroi and Kamilaroi people of Tamworth and Walgett, and the Awabakal and Worimi people of Newcastle. The authors wish to pay respect to their Elders both past and present, and extend that respect to any Indigenous readers. They thank Drs Keith Hollebone, Ken Apen and Tony Gerathy for their assistance in the obstetric clinics to recruit participants. For their invaluable contributions to the study the authors would like to thank Megan Naden, Aunty Pearl Slater, Camilla Maxwell, Lyniece Keogh, Alexis Hure, Julie Burrows, Stella Sands, Trishy Weatherall and members of the Gomeroi gaaynggal Steering Committee. The assistance of the antenatal team and other staff members from the Walgett Aboriginal Medical Service has been invaluable. The authors are grateful to the University of Newcastle Department of Rural Health Writers group (Tamworth) for their advice on this paper.

With great appreciation the authors would like to recognize the women and children who dedicate their time to participate in the Gomeroi gaaynggal study.

\section{Financial Support}

This work was supported by the National Health and Medical Research Council (grant numbers 569239, 1026733, 1063123), the Hunter Medical Research Institute and Kidney Health Australia.

\section{Conflicts of Interest}

None.

\section{Ethical Standards}

The authors assert that all procedures contributing to this work comply with the ethical standards of the relevant national guidelines on human experimentation (the National Statement on Ethical Conduct in Human Research, Values and Ethics: Guidelines for Ethical Conduct in Aboriginal and Torres Strait Islander Health Research), and with the Helsinki Declaration of 1975, as revised in 2008, and has been approved by the institutional committees; the Hunter New England Human Research Ethics Committee (reference number 08/05/21/4.01); the New South Wales Human Research Ethics Committee (reference number HREC/08/HNE/129); and the Aboriginal Health and Medical Research Council (reference number 654/08).

\section{References}

1. United Nations Permanent Forum on Indigenous Issues. Who are indigenous peoples?. United Nations. Retrieved 19 December 2014 from http://www.un.org/esa/socdev/unpfii/documents/ 5session_factsheet1.pdf.

2. World Health Organization. Health of indigenous peoples, fact sheet no. 326. 2007. Retrieved 19 December 2014 from http:// www.who.int/mediacentre/factsheets/fs326/en/.

3. World Health Organization. Indigenous peoples' right to health. Retrieved 19 December 2014 from http://www.who.int/hhr/ activities/indigenous_peoples/en/.

4. Smylie J, Crengle S, Freemantle J, Taualii M. Indigenous birth outcomes in Australia, Canada, New Zealand and the United States - an overview. TOWHJ. 2010; 4, 7-17.

5. Australian Institute of Health and Welfare. Mortality and Life Expectancy of Indigenous Australians 2008 to 2012, 2014. Australian Government: Canberra.

6. Australian Bureau of Statistics. The Health and Welfare of Australia's Aboriginal and Torres Strait Islander Peoples, 2005. Commonwealth of Australia: Canberra, Australia.

7. Australian Bureau of Statistics. Australian Aboriginal and Torres Strait Islander Health Survey: Updated Results, 2012-3, 2014. Australian Bureau of Statistics: Canberra, Australia. 
8. Australian Institute of Health and Welfare. Aboriginal and Torres Strait Islander Health Performance Framework 2014 Report: Detailed Analyses, 2015. Australian Institute of Health and Welfare: Canberra.

9. Hilder L, Zhichao Z, Parker M, Jahan S, Chambers G. Australia's Mothers and Babies 2012, 2014. Australian Institute of Health and Welfare, Canberra Australian Institute of Health and Welfare: Canberra, Australia.

10. Australian Bureau of Statistics. Australian Aboriginal and Torres Strait Islander Health Survey: Nutrition Results - Food and Nutrients, 2012-13, 2015. Australian Bureau of Statistics: Canberra.

11. Barker D, Godfrey K, Gluckman P, et al. Fetal nutrition and cardiovascular disease in adult life. The Lancet. 2003; 341, 938-941.

12. Barker D. Fetal origins of coronary heart disease. Br Med J. 1995; 311, 171-174.

13. Barker D. Maternal nutrition, fetal nutrition, and disease later in life. Nutrition. 1997; 13, 807-813.

14. Hoy W, Hughson M, Singh G, Douglas-Denton R, Bertram J. Reduced nephron number and glomerulomegaly in Australian Aborigines: a group at high risk for renal disease and hypertension. Kidney Int. 2006; 70, 104-110.

15. Australian Bureau of Statistics. Australian Aboriginal and Torres Strait Islander Health Survey: Biomedical Results, 2012-13, 2014. Australian Bureau of Statistics: Canberra. Retrieved 10 September 2014 from http://www.abs.gov.au/ausstats/abs@.nsf/Lookup/by\% 20Subject/4727.0.55.003 2012-13-Main\%20Features -Key\% 20Findings $\sim 1$.

16. Kramer M, Lydon J, Goulet L, et al. Maternal stress/distress, hormonal pathways and spontaneous preterm birth paediatric and perinatal epidemiology. Paediatr Perinat Epidemiol. 2013; 27, 237-246.

17. McLean M, Bisits A, Davies J, et al. A placental clock controlling the length of human pregnancy. Nat Med. 1995; 1, 460-463.

18. Australian Bureau of Statistics. Estimates of Aboriginal and Torres Strait Islander Australians, June 2011, 2013. Australian Bureau of Statistics: Canberra.

19. Australian Bureau of Statistics. Tamworth Region. Australian Bureau of Statistics. Retrieved September 2014 from http://stat. abs.gov.au/itt/r.jsp? RegionSummary\&region $=110041205 \&$ dataset=ABS_NRP9_ASGS\&geoconcept=REGION\&measure $=$ MEASURE $\&$ datasetASGS=ABS_NRP9_ASGS\&datasetLGA =ABS_NRP9_LGA\&regionLGA=REGION\&regionASGS= REGION.

20. Australian Bureau of Statistics. Newcastle LGA. Australian Bureau of Statistics. Retrieved September 2014 from http://stat.abs. gov.au/itt/r.jsp?RegionSummary\&region $=15900 \&$ dataset=ABS_ NRP9_LGA\&geoconcept=REGION\&maplayerid=LGA2012\& measure $=$ MEASURE $\&$ datasetASGS $=$ ABS_NRP9_ASGS \& datasetLGA=ABS_NRP9_LGA\&regionLGA=REGION\& regionASGS $=$ REGION.

21. Office of Communities Aboriginal Affairs. Community Portrait: Walgett. 2011. NSW Government: Australia. Retrieved 4 Sepetember 2014 from http://aboriginalaffairs.nsw.gov.au/wpcontent/uploads/2012/11/Community-Portrait-2011B-Walgett. pdf.
22. Rae K, Weatherall L, Hollebone $\mathrm{K}$, et al. Developing research in partnership with Aboriginal communities - strategies for improving recruitment and retention. Rural Remote Health. 2013; 13.

23. Dinkel E, Ertel M, Diettrich N, et al. Kidney size in childhood: sonographical growth charts for kidney length and volume. Pediatr Radiol. 1985; 15, 38-43.

24. Collins C, Watson J, Guest M, et al. Reproducibility and comparative validity of a food frequency questionnaire for adults. Clin Nutr. 2014; 33, 906-914.

25. Watson J, Collins C, Sibbritt D, Dibley M, Garg M. Reproducibility and comparative validity of a food frequency questionnaire for Australian children and adolescents. Int J Behav Nutr Phys Activity. 2009; 6, doi:10.1186/1479-5868-6-62.

26. Eyeson-Annan M. Monitoring child health in NSW: the New South Wales Child Health Survey 2001 and Beyond. NSW Public Health Bull. 2002; 13, 239-240.

27. Australian Bureau of Statistics. National Nutrition Survey: Nutrient Intakes and Physical Measurements, 1998. Australian Bureau of Statistics: Canberra.

28. Webb K, Marks G, Lund-Adams M, Rutishauser I, Abraham B. Towards a National System for Monitoring Breastfeeding in Australia: Recommendations for Population Indicators, Definitions and Next Steps, 2001. Commonwealth Department of Health and Aged Care, Australian Food and Nutrition Monitoring Unit: Canberra.

29. Hure A, Collins C, Giles W, Wright I, Smith R. Protocol for the Women And Their Children's Health (WATCH) study: a cohort of pregnancy and beyond. J Epidemiol. 2012.

30. Australian Institute of Health and Welfare. Measuring the Social and Emotional Wellbeing of Aboriginal and Torres Strait Islander Peoples, 2009. AIHW: Canberra.

31. Wadhwa PD. Psychoneuroendocrine processes in human pregnancy influence fetal development and health. Psychoneuroendocrinology. 2005; 30, 724-743.

32. McNamara B, Banks E, Gubhaju L, et al. Measuring psychological distress in older Aboriginal and Torres Strait Islanders Australians: a comparison of the K-10 and K-5. Aust N Z J Public Health. 2014; 38, 567-573.

33. Stewart A, Marfell-Jones M, Olds T, de Ridder H. International Standards for Anthropometric Assessment, 2011. New Zealand International Society for the Advancement of Kinanthropometry: Lower Hutt, New Zealand.

34. Diabetes Australia. Gestational diabetes. 2014. Retrieved 3 December 2014 from www.diabetesaustralia.com.au/Livingwith-Diabetes/Gestational-Diabetes/.

35. National Health and Medical Research Council. The NHMRC RoadMap: A Strategic Framework for Improving Aboriginal and Torres Strait Islander Health Through Research, 2003. Commonwealth of Australia: Canberra.

36. Gardosi J, Francis A. Customised Weight Centile Calculator: GROW version 6.7 (UK). Gestation Network, 2013. Retrieved 17 December 2014 from www.gestation.net.

37. Pathology North Handbook. NSW Government Health Pathology. Retrieved 19 December 2014 from http://www. palms.com.au/php/labinfo/index.php. 